\title{
Evaluation of Health and Happiness of Mothers of Children with Sleep Disorders
}

\author{
Mohammad Khademloo ${ }^{1}$, Seyyed Mohammad Moosavi ${ }^{2}$, Mahshid Ahmadi ${ }^{1,}$, \\ ${ }^{1}$ Department of Social Medicine, Mazandaran University of Medical Sciences, Sari, Iran \\ ${ }^{2}$ Department of Psychiatry, Mazandaran University of Medical Sciences, Sari, Iran
}

Email address:

m.ahmadi@mazums.ac.ir (M. Ahmadi)

${ }^{*}$ Corresponding author

\section{To cite this article:}

Mohammad Khademloo, Mahshid Ahmadi, Seyyed Mohammad Moosavi. Evaluation of Health and Happiness of Mothers of Children with Sleep Disorders. European Journal of Preventive Medicine. Vol. 5, No. 1, 2017, pp. 19-22. doi: 10.11648/j.ejpm.20170501.12

Received: December 27, 2016; Accepted: January 17, 2017; Published: February 22, 2017

\begin{abstract}
Aim: The aim of this study was to evaluate the overall health and happiness of healthy mothers of children with sleep disorder. Methods and material: This study was cross sectional study. To collect data from general health questionnaire (GHQ -28) with 28 questions and four subscales (somatic disorders, anxiety, social dysfunction and depression) and Oxford happiness questionnaire on five factors (satisfaction life, positive mood, health, and self-efficacy) with 29 questions was used. To analyze the data, independent t-test was used. Result: The results showed that the overall health and happiness of mothers of children with sleep disorder were affected by their children disorder. Conclusion: Mothers' health is associated with and affected by their children and sleep disorders in children reduce the quality of life in mothers.
\end{abstract}

Keywords: Health, Happiness, Mothers, Children, Sleep Disorder

\section{Introduction}

Sleep disorders affect $15-25 \%$ of the preschool aged population [1] and can lead to psychological, physical, behavioral and academic disorders $[2,3]$. Sleep is a part of body development and is major part of the time between 2 to 5 years even more than learning [4].

Sleep disorders in children may affect the parents especially their mothers and make them unhappy. Herein, majority of investigations were performed on depression, anxiety or other mental disorders $[5,6,7,8]$. Bayer JK et al [9] studied 692 mothers and their infants. They reported Sleep disorders are common in early infancy across metropolitan socio-economic levels and are in relations with poorer maternal health and well-being. Recently, self-rating evaluations using different scales have become important to improve the doctors in evaluation and finding psychiatric comorbidities in patients. [10,11-14].

Mental health is of the basic human needs and its role in various spheres of life, social, work, family and society is undeniable and its purpose is, ultimately creating a healthy environment for proper human relations.
Considering that public health and the happiness of parents, especially mothers play an important role in the lives of their children, so, we decided to examine public health and welfare of mothers of children with sleep disorder take a step towards health. Rare papers discussed about the effect of children sleep disorders on their mothers and the effect is not well established. Therefore in this study we examined the prevalence of these disorders in mothers using questioners.

\section{Methods and Material}

Cross-sectional study was carried which the study population included the mothers of students with sleep disorders during 2015 to 2016 from sari, Iran. The sample frame consisted of Iranian mothers aged 18.

We used simple sampling method for collecting cases including 100 mothers.

Exclusion criteria

The following cases have been excluded:

i. Non-Iranians citizens (for the purpose of homogeneity). 
ii. Those unwilling to answer the questionnaire.

iii. Cases with communication difficulties; e.g. deafness, blindness, muteness.

\section{Ethical notes}

The study population voluntarily participated in the investigation. Written consent was obtained from the participants for publication of the research results. All subjects signed consent forms in the presence of a witness for all evaluations applied.

\section{Translation of the Questionnaires}

The questionnaires were translated from English to Farsi. To ensure that the Farsi translation showed the meaning in the English Type, back-translation was consider with the help of one translator in the English and the crucial changes were performed.

Questioner were used in this study

GHQ-28: The GHQ-28 Questioner improved by Goldberg consisted of 28 items fulfilled in only 10-12 min. The scale aim to evaluate 4 areas of psychiatric morbidity containing somatization, anxiety, social dysfunction, and depression, and indicates overall mental health at a specific point in time, as well. Each question has four answer categories including "better than usual"; "same as usual as";" worse than usual"; or "much worse than usual". Participants answer each item based on how they have recently felt their experience. The higher GHQ-28 scores is correlated with higher level of psychiatric problems $[15,16]$.

Children's sleep habits questionnaire (CSHQ)

CSHQ were used to determine sleep quality in cases. The CSHQ indicates common sleep disorders in children aged 212 years and includes 33 items and 8 subscales. The items are rated on a 3 -scored Likert scale (rarely $=0-1$ night per week; sometimes $=2-4$ nights per week; usually $=5-7$ nights per week). Every question correlate with the previous week, and is ranked as 0,1 and 2, respectively. A total score of more than 33 is the cut off and reveals sleep disorders and sleep problems in children [19-23].

\section{The Oxford Happiness Inventory (OHI)}

$\mathrm{OHI}$ is a 29-item questionnaire which examines happiness in participants. Questions are rated in 6-point Likert scale from $1=$ strongly disagree to $6=$ strongly agree. The highest score is from 29 to 174 . A high score reveal more happiness. The OHI had a reliable reliability with $\alpha$ : 0.92 , and it had a strong internal consistency to measurement of happiness in the cases $(\mathrm{P}<0.001)$ [24]. Some investigations have indicated $\mathrm{OHI}$ has had enough validity and reliability [25, 26, 27].

Statistics

Researchers assess the reliability of the questionnaire $b$ Cronbach's alpha coefficient. Independent $t$ test were used to examine the research hypotheses. $\mathrm{P}$ value off less than 0.05 was defined as significant.

\section{Results}

According to our study, $27 \%$ of subjects aged less than 30 years, 5.69 percent were in the age group between 30 to 40 years and 5.3 percent were in the age group over 40 years.
Table 1. Demographic results of study populations.

\begin{tabular}{lll}
\hline age & number & percent \\
\hline Less than 30 & 28 & 28 \\
$30-40$ & 69 & 69 \\
More than 40 & 3 & 3 \\
total & 100 & 100 \\
\hline
\end{tabular}

$13.5 \%$ of subjects with primary education, $44.5 \%$ of elementary, 37.5 percent diplomas, 3.5 percent bachelor and 1 percent have master of sciences.

$6 \%$ of subjects were self-employed, 32 percent had government jobs and $62 \%$ were housewives.

Public health variables (mental) in mothers of children with sleep disorder was $13.01 \%$. This indicates that the average mental health in mothers of children with sleep disorders was high. Happiness variable in mothers of children with sleep disorder was $37.8 \%$.

Question number one: Is there a difference between the healths of mothers of children with sleep disorders? Mean \pm $\mathrm{SD}$ answer score was $13.01 \pm 5.4$. In other words, public health in mothers of children with sleep disorder is significantly higher than mothers of healthy children.

Question number two: Is there a difference between the happiness of mothers of children with sleep disorder? Mean \pm SD answer score was $37.85 \pm 16.3$. There were significant differences between happiness of healthy mothers of children with sleep disorder.

Question number three: Is there a difference between physical disorders of mothers of children with sleep disorder? Mean \pm SD answer score was $2.92 \pm 1.7$. There is no significant difference among mothers of children with sleep disorder.

Question four: Is there a difference between anxieties in mothers of children with sleep disorder? Mean \pm SD answer score was $2.8 \pm 1.9$. In other words, the level of anxiety in mothers of children with sleep disorder is higher.

Question number five: Is there a difference between social dysfunction of mothers of children with sleep disorder? Mean $\pm \mathrm{SD}$ answer score was $4.5 \pm 2.1$. There is no significant difference in Social dysfunction among mothers of children with sleep disorder.

Question number six: Is there a difference between depressions in mothers of children with sleep disorder? Mean \pm SD answer score was $2.7 \pm 2.3$. Depression in mothers of children with sleep disorder was high.

\section{Discussion}

Our study revealed that sleep disorders in children would affect the quality of life in their mothers. In this regards, studies showed that sleep disorders are correlated with changed psychomotor performance [28], behavioral disturbance [29], sleepiness [30, 31], low physical activity and social interest [31], memory and learning deficits [32], and substance abuse [33].

In this regards, the rate of bedtime problems seems to be similar among Iranian [34] and Finnish [35] children.

In a study by Montgomery $\mathrm{P}$ et al [36] examined 45 
children (aged 3-14 years) with ADHD and their mothers. They indicated maternal mental health was found to be significantly worse in the mothers who thought their children to be sleepless (Maternal definition MD).

In a paper by Roth B et al [37] checked 59 obese children with their mothers. The results showed that maternal anxiety predicted the mother indicated child's internalizing disorders beside the child's depression and anxiety self-report scores. The mental disorder status of the mother could reveal the child's internalizing disorders, and maternal binge eating disorder had an effect on the mental disorder of the pediatrics.

\section{Limitations of the Study}

Limiting the population of mothers with sleep disorders and normal pre-school students to Sari populations. Data were collected through questionnaires only. The subjects involved personal opinions in response to questions

\section{Conclusion}

It is recommended that officials with perform scientific planning and integrated mental health and happiness to parents Especially mothers of children with sleep disorder after deciding to thereby improve sleep disorders in children.

\section{References}

[1] Owens J. Classification and epidemiology of childhood sleep disorders. Primary Care Clinics in Office Practice. 2008;35: 533-546. [PubMed]

[2] Gregory A, Van der Ende J, Willis T, Verhulst F. Parentreported sleep problems during development and self-reported anxiety/depression, attention problems, and aggressive behavior later in life. Archives of Pediatric \& Adolescent Medicine. 2008;162:330-335. [PubMed]

[3] Wong M, Brower K, Zucker R. Childhood sleep problems, early onset of substance use and behavioral problems in adolescence. Sleep Medicine. 2009;10: 787-796. [PMC free article] [PubMed]

[4] Matricciani L, Blunden S, Rigney G, Williams MT, Olds TS. Children's sleep needs: Is there sufficient evidence to recommend optimal sleep for children? Sleep. 2013;36 (4): 527-534. [PMC free article] [PubMed]

[5] Diener E, Oishi S, Lucas RE. 17 Subjective Well-Being: The Science of Happiness and Life Satisfaction. USA: Oxford University Press; 2009. p. 187.

[6] Abdollahi A, Abu Talib M. Self-esteem, body-esteem, emotional intelligence, and social anxiety in a college sample: The moderating role of weight. Psychol Health Med. 2015:15. doi: 10.1080/13548506.2015.1017825. [PubMed] [Cross Ref]

[7] Bolonkin A. Universe, human immortality and future human evaluation. Amsterdam, Netherlands: Elsevier; 2011.
[8] Lyubomirsky S, King L, Diener E. The benefits of frequent positive affect: does happiness lead to success? Psychol Bull. 2005; 131 (6): 803-55. doi: 10.1037/0033-2909.131.6.803. [PubMed] [Cross Ref]

[9] Bayer JK, Hiscock H, Hampton A, Wake M. Sleep problems in young infants and maternal mental and physical health. J Paediatr Child Health. 2007 Jan-Feb; 43 (1-2): 66-73.

[10] Anderson JG, Taylor AG. (2011). The metabolic syndrome and mind-body therapies: a systematic review. J Nutr Metab, 2011: 276419. [PMC free article] [PubMed]

[11] Daubenmier J, Kristeller J, Hecht FM, Maninger N, Kuwata M, Jhaveri K, Lustig RH, Kemeny M, Karan L, Epel E. (2011). Mindfulness Intervention for Stress Eating to Reduce Cortisol and Abdominal Fat among Overweight and Obese Women: An Exploratory Randomized Controlled Study. J Obes, 2011: 651936. [PMC free article] [PubMed]

[12] Leverone D, Epstein BJ. (2010). Nonpharmacological interventions for the treatment of rheumatoid arthritis: a focus on mind-body medicine. J Pharm Pract, 23 (2): 101-9. [PubMed]

[13] Purdy J. (2013). Chronic physical illness: a psychophysiological approach for chronic physical illness. Yale J Biol Med, 86(1): 15-28. [PMC free article] [PubMed]

[14] Ross A, Thomas S. (2010). The health benefits of yoga and exercise: a review of comparison studies. J Altern Complement Med, 16 (1): 3-12. [PubMed]

[15] Noorbala AA, Bagheri Yazdi SA, Mohammad K. (2009). The Validation of General Health Questionnaire-28 as a Psychiatric Screening Tool. Hakim Res J, 11: 47-53.

[16] Goldberg DP, Hillier VF. (1979). A scaled version of the General Health Questionnaire. Psychol Med, 9 (1): 139-145. [PubMed]

[17] Owens JA, Spirito A, McGuinn M. The Children's Sleep Habits Questionnaire (CSHQ): psychometric properties of a survey instrument for school-aged children. Sleep. 2000;23: 1043-1051. [PubMed]

[18] LiuX LL, Owens JA, Kaplan DL. Sleep patterns and sleep problems among schoolchildren in the United States and China. Pediatrics. 2005; 115 (1): 241-249. doi: 10.1542/peds.2004-0815F. [PubMed]

[19] Jallilolgadr SH, Hashemi S, Javadi M, Esmailzadeh N, Jahanihashami H, Afagi A. Sleep habit of Iranian pre-school children in urban area: Late sleeping and sleep debt in children. Sleep Biol Rhythms. 2011; 10 (2): 154-156. doi: 10.1111/j.1479-8425.2011.00516.x.

[20] Rafii F, Oskouie F, Shoghy M. The Association between Sleep and Injury among School-Aged Children in Iran. Sleep Dis. 2013; 2013 doi: 10.1155/2013/891090. [PMC free article] [PubMed]

[21] Shoghy M, Khangary S, Farmany F, Hosseini F. Sleep habit of school age chidren. Iran J Nursing. 2004; 18 (41, 42): 131138.

[22] MohammadI M, Amintehrani E, Ghaleh-Bandi MF, Ashrafi MR, Shoaee S, Ghalehbaghi B. Reliability and validity of persian version of "BEARS" pediatric Sleep Questionar. Indian J Sleep Med. 2088; 3 (1): 14-19. 
[23] Moore M, Meltzer LJ, Mindell JA. Bedtime Problems and Night Wakings in Children. Prim Care. 2008; 35 (3): 569581. doi: 10.1016/j.pop.2008.06.002. [PubMed]

[24] Hills P, Argyle M. The Oxford Happiness Questionnaire: a compact scale for the measurement of psychological wellbeing. Pers Individ Differ. 2002; 33 (7): 1073-82. doi: 10.1016/S0191-8869 (01)00213-6. [Cross Ref]

[25] Chamorro-Premuzic T, Bennett E, Furnham A. The happy personality: Mediational role of trait emotional intelligence. Pers Individ Differ. 2007; 42 (8): 1633-9. doi: 10.1016/j.paid.2006.10.029. [Cross Ref]

[26] Faribors B, Fatemeh A, Hamidreza H. The relationship between nurses' spiritual intelligence and happiness in Iran. Proc-Soc Behav Sci. 2010; 5: 1556-61.

[27] Pishva N, Ghalehban M, Moradi A, Hoseini L. Personality and Happiness. Proc-Soc Behav Sci. 2011;30: 429-32.

[28] Anders TF, Keener MA, Kraemer H. Sleep-wake state organization, neonatal assessment and development in premature infants during the first year of life. II. Sleep. 1985;8: 193-206. [PubMed]

[29] Thoman EB, Denenberg VH, Sievel J, Zeidner LP, Becker P. State organization in neonates: Developmental inconsistency indicates risk for developmental dysfunction. Neuropediatrics. 1981;12: 45-54. [PubMed]

[30] Carskadon MA. In: Sleeping and waking disorders: Indications and techniques. Guilleminault $\mathrm{C}$, editor. Menlo Park, CA: Addison Wesley; 1982. pp. 99-125.
[31] Carskadon MA, Harvey K, Duke P, Anders TF, Litt IF, Dement WC. Pubertal changes in daytime sleepiness. Sleep. 1980;2: 453-460. [PubMed]

[32] Carskadon MA, Acebo C, Jenni OG. Regulation of adolescent sleep: Implications for behavior. Ann N Y Acad Sci. 2004 Jun; 1021: 276-291. [PubMed]

[33] Carskadon MA. Patterns of sleep and sleepiness in adolescents. Pediatrician. 1990; 17 (1): 5-12. [PubMed]

[34] Jallilolgadr SH, Hashemi S, Javadi M, Esmailzadeh N, Jahanihashami H, Afagi A. Sleep habit of Iranian pre-school children in urban area: Late sleeping and sleep debt in children. Sleep Biol Rhythms. 2011;10 (2): 154-156. doi: 10.1111/j.1479-8425.2011.00516.x.

[35] Simola P, Niskakangas M, Liukkonen K, Virkkula P, Pitk ranta A, Kirjavainen T, et al. Sleep problems and daytime tiredness in Finnish preschool-aged children-a community survey. Child: Care. Health Dev. 2010; 36 (6): 805-811. doi: 10.1111/j.1365-2214.2010.01112. [PubMed]

[36] Montgomery P, Wiggs L. Definitions of sleeplessness in children with attention-deficit hyperactivity disorder (ADHD): implications for mothers' mental state, daytime sleepiness and sleep-related cognitions. Child Care Health Dev. 2015 Jan;41 (1): 139-46. doi: 10.1111/cch.12165. Epub 2014 Jun 12.

[37] Roth B, Munsch S, Meyer A, Isler E, Schneider S. The association between mothers' psychopathology, childrens' competences and psychological well-being in obese children. Eat Weight Disord. 2008 Sep; 13 (3): 129-36. 